\title{
Comparative features of infections of two Massachusetts (Mass) infectious bronchitis virus (IBV) variants isolated from Western Canadian layer flocks
}

Aruna Amarasinghe ${ }^{1}$, Upasama De Silva Senapathi', Mohamed Sarjoon Abdul-Cader ${ }^{1}$, Shelly Popowich², Frank Marshall ${ }^{3}$, Susan C. Cork', Frank van der Meer', Susantha Gomis ${ }^{2}$ and Mohamed Faizal Abdul-Careem ${ }^{1 *}$ (D)

\begin{abstract}
Background: Infectious bronchitis virus (IBV) is one of the leading causes of mortality and morbidity in chickens. There are numerous serotypes and variants, which do not confer cross protection resulting in failure of currently used IBV vaccines. Although variant IBV isolates with major genetic differences have been subjected to comparative studies, it is unknown whether minor genetic differences in IBV variants within a serotype are different in terms of pathogenesis and eliciting host responses. Two Massachusetts (Mass) variant IBV isolates recovered from commercial layer flocks in the Western Canadian provinces of Alberta (AB) and Saskatchewan (SK) were compared genetically and evaluated for their pathogenicity, tissue distribution and ability to recruit and replicate in macrophages.

Results: Although whole genome sequencing of these two Mass IBV isolates showed low similarity with the M41 vaccinal strain, they had an identical nucleotide sequence at open reading frames (ORFs) 3a, 3b, envelop (E), matrix (M), 5a and 5b. The rest of the ORFs of these 2 IBV isolates showed 99.9\% nucleotide similarity. However, upon experimental infection, we found that the IBV isolate originating from AB was different to the one that originated in SK due to higher tracheal lesion scores and lower lung viral replication and lower genome loads in cecal tonsils. Nevertheless, both IBV isolates elicited host responses characterized by significant macrophage recruitment to the respiratory tract and there was evidence that both IBV isolates replicated within tracheal and lung macrophages.

Conclusions: Overall, this study shows that Mass variant IBV isolates, although possessing minor genetic variations, can lead to significant differences in pathogenicity in young chickens. Further studies are required to investigate the pathogenicity of these two Mass variant IBV isolates in laying hens.
\end{abstract}

Keywords: Infectious bronchitis virus, Whole genome sequencing, Tissue distribution, Pathogenicity, Macrophage response

\section{Background}

Infectious bronchitis virus (IBV) belongs to the family Coronaviridae. Traditionally, IBV is considered to be a host-specific respiratory pathogen in chickens and IBV initially replicates at the route of entry, the tracheal mucosa $[1,2]$. However, identification of new variants and/ or serotypes of IBV have shown a wide variation of tissue tropism including urinary [3-10], gastrointestinal

\footnotetext{
* Correspondence: faizal.abdulcareem@ucalgary.ca

${ }^{1}$ Department of Ecosystem and Public Health, Faculty of Veterinary Medicine, University of Calgary, Health Research Innovation Center 2C53, 3330 Hospital Drive NW, Calgary, AB T2N 4N1, Canada

Full list of author information is available at the end of the article
}

$[6,9,11,12]$, oviduct $[9,13]$ and bursa of Fabricius $[11,14]$. IBV is known to replicate in the reproductive tract epithelium in layers leading to reduced egg production and shell defective eggs $[15,16]$. False layer syndrome, which is associated with cystic oviduct formation occurs with IBV infection in early life $[17,18]$. IBV can also replicate in the testes of cockerels [19].

An array of serotypes and strains of IBV infect chickens throughout the world [2]. Genetic events such as insertion(s) and deletions [20,21], point mutations [22], and recombination [23-27] contribute to genomic variations of IBV [28]. The spike 1 (S1) gene is highly

(c) The Author(s). 2018 Open Access This article is distributed under the terms of the Creative Commons Attribution 4.0 International License (http://creativecommons.org/licenses/by/4.0/), which permits unrestricted use, distribution, and 
variable among IBV strains and it encodes epitopes, which bind to neutralizing antibodies [29]. A change in the amino acid sequence as small as 2 to $3 \%$ in the $\mathrm{S} 1$ subunit can result in changes in the antigenicity of the virus [30]. Based on these changes of the S1 protein, numerous IBV strains have been characterized throughout the world [1]. Therefore, either the partial [31-33] or the full-length [34-39] of the S1 glycoprotein gene has been used in the molecular characterization of IBV isolates. However, using whole genome sequencing it has been observed that genes other than S1 may play a role in the pathogenicity of IBV infection [40, 41]. Currently, there are no IBV reference full genome sequences available for Canadian IBV isolates but partial [33] or complete [37] S1 sequences are available.

Previously, comparative studies have been conducted to elucidate differential pathogenicity and host responses between variant IBV isolates with larger genome variability such as nephropathogenic and Massachusetts (Mass) IBV isolates recovered from various geographical areas $[18,42-46]$. Since it is well known that very minor changes in the genome of viruses [47] including IBV $[48,49]$ can lead to difference in pathogenicity, comparative studies involving variant IBV isolates are required.

A wide array of IBV variants are affecting commercial broiler, layer and breeder flocks in Canada [33, 37, 50, 51]. For example, Mass type IBV variants are impacting the commercial egg production in Western Canada [50]. This study showed that Mass type IBV infection of 27-week old layers at peak production, lead to loss of egg production for about 2 weeks followed by production of shell less, small and defective eggs for another 2 days before the egg production bounced back to normal production. The duration of the loss of marketable eggs appears to be 16 days. In an 8000 bird layer flock of Western Canada, we observed $47.6 \%$ drop in egg production for 10 days and we isolated a Mass type variant IBV from this flock. Based on Egg Farmers of Alberta's price of $\$ 2.15 /$ dozen of large eggs, the loss for 10 days is calculated to be $\$ 6823$ for this particular outbreak and the loss will be higher if the infection persists beyond 10 days or reoccur. In addition to this direct loss of egg production, egg grading stations need to outsource supply of eggs during these production drops and also some of the affected birds may succumb to secondary bacterial infections without a recovery, hence the indirect losses are substantially higher than the direct costs of IBV infection.

The present study was conducted with the aim to elucidate the genetic differences of two Mass variant IBV isolates (15AB-01 and 15SK-02) that originated from layer flocks in Western Canada, Alberta (AB) and Saskatchewan (SK). Additionally, we aimed to describe whether these genetic changes in Mass isolates 15AB-01 and 15SK-02 lead to differential pathogenicity, tissue distribution and macrophage responses in the respiratory tract.

\section{Results \\ Molecular characterization of the mass IBV isolates, 15AB-01 and 15SK-02}

For the isolate $15 \mathrm{AB}-01$, total of 525,998 and 908,860 read sets were obtained from the direct allantoic fluid sample and layered virus sample, respectively from the Illumina MiSeq workflow. From these, a total of 418,446 and 825,147 reads were aligned with the reference IBV genomes. For isolate 15SK-02, a total of 4,355,902 and $3,731,578$ reads were obtained from the direct allantoic fluid sample and layered virus sample, respectively, of which, a total of 3,146,584 and 3,152,622 reads were aligned with the IBV reference genomes. The number of reads obtained from Illumina MiSeq for 15SK-02 was 10 times higher than for 15AB-01 and the viral genome concentration of the submitted complimentary (c)DNA was also much higher for 15SK-02 than for 15AB-01 (real-time PCR cycle threshold or Ct value difference of 3.54). Entirely based on the NGS output, the complete genomes obtained for the Mass IBV isolates, 15AB-01 and $15 \mathrm{SK}-02$ were $27.6 \mathrm{~kb}$ in length. As determined by the open reading frames (ORF) predictor, both isolates had similar genome organization with 11 ORFs and they were $5^{\prime}-1 \mathrm{a}-1 \mathrm{~b}-\mathrm{S}-3 \mathrm{a}-3 \mathrm{~b}-\mathrm{E}-\mathrm{M}-5 \mathrm{a}-5 \mathrm{~b}-\mathrm{N}-3^{\prime}$ (Table 1). Between the isolates, $15 \mathrm{AB}-01$ and $15 \mathrm{SK}-02$, there was 99.9\% nucleotide similarity. With the M41 vaccine strain, 15AB-01 and 15SK-02 shared a genetic similarity of 92.8 and $92.7 \%$, respectively. 15AB-01 and 15SK-02 Mass IBV isolates shared 92.8 and $92.7 \%$ nucleotide similarity with the M41 vaccine strain (GQ504725), respectively. Nucleotide similarities between Mass IBV isolates, $15 \mathrm{AB}-01$ and $15 \mathrm{SK}-02$ across the ORFs $3 \mathrm{a}, 3 \mathrm{~b}, \mathrm{E}$, $\mathrm{M}, 5 \mathrm{a}$ and $5 \mathrm{~b}$ were $100 \%$. The remainder of genes were over 99\% identical (Table 2). Nucleotide similarities

Table 1 Genes, coding regions, and deduced proteins of the current Mass IBV isolates, 15AB-01 and 15SK-02

\begin{tabular}{lllll}
\hline Gene & $\begin{array}{l}\text { Translation } \\
\text { Frame }\end{array}$ & Gene location & $\begin{array}{l}\text { Nucleotide } \\
\text { length (bp) }\end{array}$ & $\begin{array}{l}\text { Number of } \\
\text { amino acids }\end{array}$ \\
\hline 1a & 1 & $529-12,390$ & 11,862 & 3953 \\
1b & 3 & $12,465-20,423$ & 7959 & 2652 \\
S & 1 & $20,374-23,862$ & 3489 & 1162 \\
3a & 3 & $23,862-24,035$ & 174 & 57 \\
3b & 2 & $24,035-24,229$ & 195 & 64 \\
E & 3 & $24,210-24,539$ & 330 & 109 \\
M & 1 & $24,511-25,188$ & 678 & 225 \\
$5 a$ & 3 & $25,539-25,736$ & 198 & 65 \\
$5 b$ & 2 & $25,733-25,981$ & 249 & 82 \\
$\mathrm{~N}$ & 1 & $25,924-27,153$ & 1230 & 409 \\
\hline
\end{tabular}


Table 2 Nucleotide similarity of 15AB-01 and 15SK-02 across various genes with M41 vaccine strain GQ504725

\begin{tabular}{|c|c|c|c|c|c|c|c|c|c|c|c|}
\hline Strain & ORF1a & ORF $1 b$ & S1 & S2 & ORF3a & ORF3b & $E$ & M & ORF5a & ORF5b & $N$ \\
\hline $15 \mathrm{AB}-01$ & 90.7 & 96.8 & 95.5 & 97.6 & 91.2 & 96.9 & 94.5 & 100 & 86.4 & 89.2 & 94.1 \\
\hline 15SK-02 & 90.6 & 96.8 & 95.5 & 97.9 & 91.2 & 96.9 & 94.5 & 100 & 86.4 & 89.2 & 94.5 \\
\hline a 15AB-01 Vs 15SK-02 & 99.9 & 99.9 & 99.6 & 99.8 & 100 & 100 & 100 & 100 & 100 & 100 & 99.5 \\
\hline
\end{tabular}

${ }^{\mathrm{a}}$ Third raw depicts the nucleotide similarities between current Mass IBV isolates 15AB-01 and 15 SK-02 across various genes

between Mass IBV isolates, 15AB-01 and 15SK-02 across the hypervariable $\mathrm{S}$ gene regions, $\mathrm{S} 1$ and $\mathrm{S} 2$, respectively were 99.6 and $99.8 \%$. The lowest nucleotide similarity these two isolates shared with the vaccine M41 strain was $86.4 \%$ in the ORF 5 a and the highest similarity was $100 \%$ in the ORF M. The S1 and S2 identities of these two IBV isolates with the M41 vaccine strain were 95.5 and $97.6 \%$, respectively (Table 2). Additionally, our IBV isolates, $15 \mathrm{AB}-01$ and $15 \mathrm{SK}-02$ were compared with important reference strains in Mass type cluster (Table 3) and they are most variable from the Beaudette IBV strain and very closely related to other Mass type IBV strains.

Full genome nucleotide distance matrix and heat maps of these isolates with 23 selected reference sequences are shown in the Fig. 1. The highest similarity of 15AB-01 and 15SK-02 shared with M41 strain (USA) was $99.9 \%$. The lowest similarity was $87.5 \%$ with the United Kingdom (UK) strain 1148 (Fig. 1). Phylogenetic reconstruction with reference IBV strains based on the full genome sequence revealed a close relation with two IBV isolates to the USA Mass type virus (Fig. 2). The isolate 15AB-01 appeared to be more recently evolved than the 15SK-02 isolate. However, clear separation of these two IBV isolates (cluster M1) from the vaccine M41 strain (Cluster M11) is evident (Fig. 2).

\section{Clinical observations and body weight changes following IBV infection of chickens}

From 2 to 8 days post-infection (dpi), there were two birds with mildly increased respiration (more labored and higher frequency) from the IBV (15AB-01) infected group. On 9 and $10 \mathrm{dpi}$, there were 3 birds with mildly increased breathing. Only one bird continued to show a mild breathing increase by $11 \mathrm{dpi}$ and thereafter all birds were bright and alert. In contrast, 2 birds from the 15SK-02 infected group started showing increased breathing as late as $7 \mathrm{dpi}$ and continued until $11 \mathrm{dpi}$. The control birds were alert and active throughout. The highest body weight gain was achieved by the uninfected control group followed by the group infected with the isolate $15 \mathrm{AB}-01$ and 15SK-02 (Fig. 3). However, the difference in bodyweights was not significant $(p>0.05)$.

\section{Histopathological changes following IBV infection of chickens}

Histopathological examination of both trachea and lung at 4 dpi showed lesions suggestive of infectious bronchitis. In the trachea, these histological changes included de-ciliation of tracheal mucosal cells, lymphoid infiltration into mucosa and underlying submucosa, and mucosal detachment from the lamina propria (Fig. 4a). Squamous metaplasia of the tracheal mucosa was prominent in trachea of both IBV infected groups (Fig. 4a). Average lesion score of the trachea infected with the isolate 15AB-01 $(p<0.001)$ and 15SK-02 $(p<0.01)$ were significantly higher than that of trachea from uninfected controls (Fig. 4b). Also lesion scores of the trachea from $15 \mathrm{AB}-01$ infected chicken were significantly higher than that of trachea from chicken infected with isolate 15SK-02 $(p<0.01)$ (Fig. 4b). In the lungs, mononuclear cell infiltration and hemorrhage into the parabronchial lumen were observed in the infected lungs compared to

Table 3 Nucleotide identities of 15AB-01 and 15SK-02 across various genes with Mass-type reference strains

\begin{tabular}{|c|c|c|c|c|c|c|c|c|c|c|c|}
\hline Strain & ORF 1a & ORF 1b & S1 & S2 & ORF 3a & ORF $3 b$ & $E$ & M & ORF $5 \mathrm{a}$ & ORF $5 b$ & N \\
\hline Beaudette & $91.5 / 91.5$ & $99.9 / 93.9$ & $97.8 / 97.8$ & $98.1 / 98.2$ & $97.7 / 97.1$ & $98.2 / 98.2$ & $98.7 / 98.7$ & $98.8 / 98.8$ & $98.9 / 98.9$ & $90.8 / 90.8$ & $92.6 / 92.7$ \\
\hline TN92-03 (India) & $93.2 / 93.2$ & $94.0 / 93.9$ & $97.2 / 97.0$ & $98.3 / 98.4$ & $97.7 / 98.3$ & $97.0 / 97.0$ & $98.4 / 98.4$ & $99.0 / 99.0$ & $100 / 100$ & $95.6 / 95.6$ & $97.6 / 99.8$ \\
\hline Mass41/1972 (USA) & $99.7 / 99.7$ & $99.5 / 99.5$ & $99.8 / 99.8$ & $99.2 / 99.3$ & $98.8 / 99.4$ & $100 / 100$ & $99.7 / 99.7$ & $99.0 / 99.0$ & $100 / 100$ & $100 / 100$ & $99.6 / 99.8$ \\
\hline Mass/USA (AY851295) & 100/99.9 & 99.9/99.9 & 99.9/99.9 & 99.9/99.9 & $100 / 99.4$ & $100 / 100$ & $99.7 / 99.7$ & $100 / 100$ & $100 / 100$ & $100 / 100$ & $99.8 / 99.6$ \\
\hline ck/CH/LHLJ/091205 (China) & 99.9/99.9 & 99.9/99.9 & $99.9 / 99.9$ & $99.9 / 99.9$ & 100/99.4 & $100 / 100$ & $100 / 100$ & $100 / 100$ & $100 / 100$ & $100 / 100$ & 100/99.8 \\
\hline M41/USA (DQ834384) & $100 / 100$ & $100 / 99.9$ & 99.9/99.9 & $99.7 / 99.7$ & 100/99.4 & $100 / 100$ & $100 / 100$ & 99.9/99.9 & $100 / 100$ & $100 / 100$ & $99.7 / 99.8$ \\
\hline Mass/USA (GQ504724) & $100 / 100$ & 99.9/99.9 & 99.9/99.9 & $99.8 / 99.8$ & 100/99.4 & $100 / 100$ & $100 / 100$ & $100 / 100$ & $100 / 100$ & $99.6 / 99.6$ & $99.8 / 99.8$ \\
\hline M41/1965 (USA) & $99.9 / 99.9$ & $100 / 100$ & 99.9/99.9 & $99.8 / 99.8$ & $98.8 / 99.4$ & $100 / 100$ & $100 / 100$ & $100 / 100$ & $100 / 100$ & $100 / 100$ & $99.6 / 99.8$ \\
\hline M41/1985 (USA) & $100 / 100$ & $99.9 / 100$ & $99.9 / 100$ & $99.8 / 99.8$ & $98.8 / 99.4$ & $100 / 100$ & $100 / 100$ & $100 / 100$ & $100 / 100$ & $100 / 100$ & $99.7 / 99.8$ \\
\hline
\end{tabular}

In each cell of the table, the first value is the nucleotide identity shared with the IBV isolate 15AB-01 and the second value is the nucleotide identity shared with the IBV isolate $15 \mathrm{SK}-02$ 


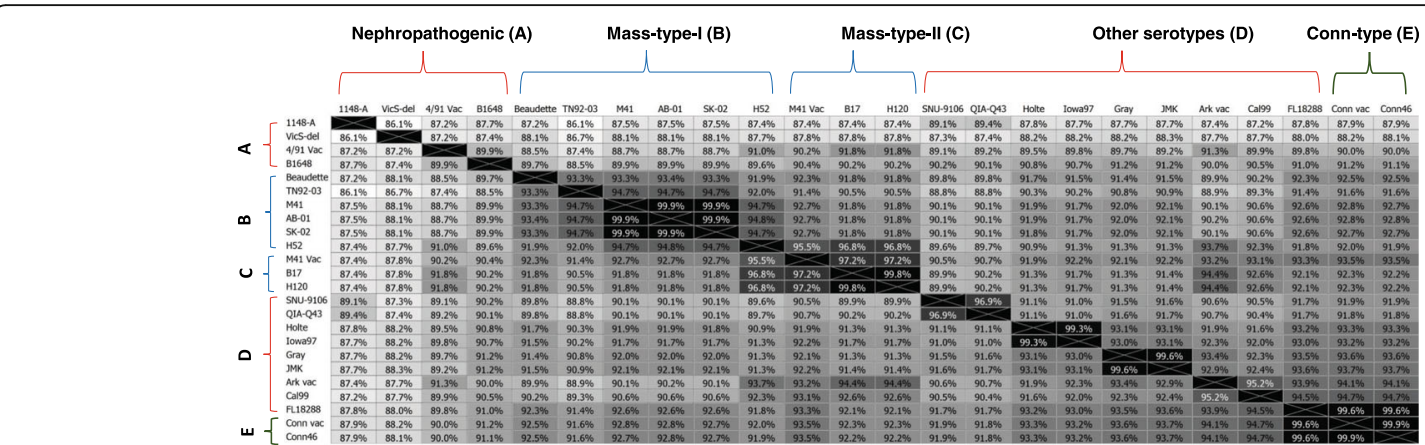

Fig. 1 Nucleotide similarity matrix and heat maps of 23-selected reference strains and 2 current Mass IBV isolates. Full genome sequences of Western Canadian isolates (15AB-01 and 15SK-02) were aligned with 23 reference sequences retrieved from the GenBank. The resulting genetic distance matrix along with heat maps based on the similarity index is shown

the uninfected controls (Fig. 4a). We observed variation in lung lesion scores within groups, yet significant outliers were not detected when the data were subjected to Grubbs test. The lung lesion scores of the lung from 15AB-01 infected chicken were significantly higher than that of the lungs from uninfected controls. However, the lung lesion score between the lung from 15SK-02 infected chicken and the uninfected controls was not statistically significant $(p>0.05)$ (Fig. 4c).

\section{IBV genome loads in oropharyngeal and cloacal swabs and tissue samples}

The average genome loads on oropharyngeal swabs were higher than the genome loads on cloacal swabs for both

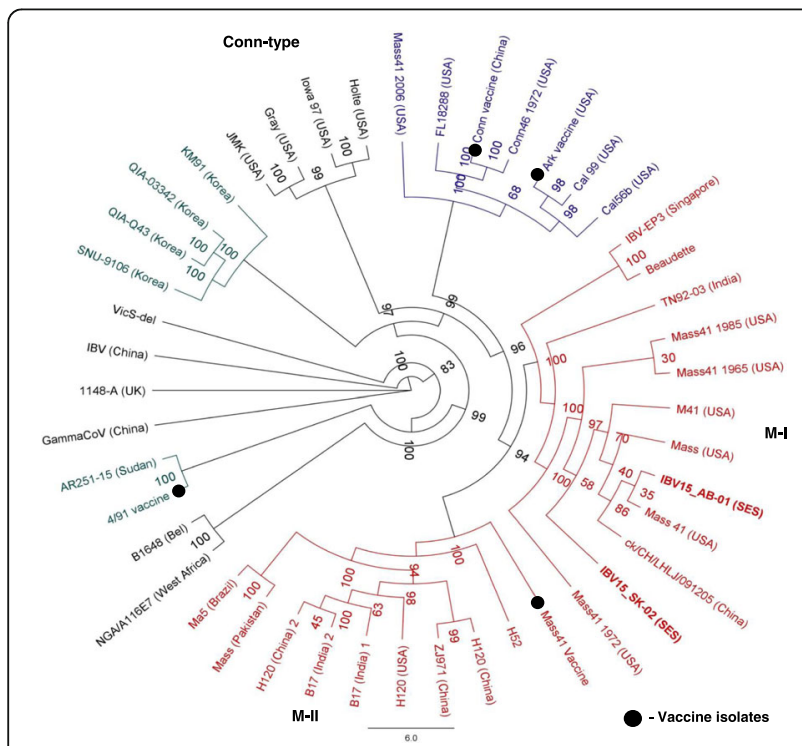

Fig. 2 Phylogenetic tree of 45 IBV whole genome sequences including Western Canadian Mass IBV isolates. A maximum likely hood phylogenetic tree was inferred based on the whole genomes of 15AB-01 and 15SK-02 isolates of IBV and 43 IBV genome sequences retrieved from GenBank using RAxML with GTR GAMMA nucleotide substitution model with 1000 bootstrap iterations
Mass IBV isolates at all time points (Fig. 5a and b). In the trachea, a genome load of $1 \times 10^{6}$ up to $3 \mathrm{dpi}$ could be detected in chicken infected with either isolate. By 12 $\mathrm{dpi}$, the genome loads in the trachea declined by 2-folds. The genome load in the cloaca was consistent for the 15AB-01 throughout the observation period. However, in the cloaca of birds infected with 15SK-02 no IBV genome at 12 dpi could be detected (Fig. 5b). No IBV genome load was detected in the uninfected controls (results not shown).

The highest genome loads in tissue were found in trachea and lung tissues of chicken infected with either isolate at $4 \mathrm{dpi}$, however, the genome load in lung tissue was significantly lower for IBV isolate 15AB-01 (Fig. 5c). At 4 and $14 \mathrm{dpi}$, the genome loads in trachea were similar for IBV isolates (15AB-01 and 15SK-02). By $14 \mathrm{dpi}$, tracheal and lung genome loads fell considerably for both isolates. Cecal tonsil genome load was declined by 14 dpi only in birds infected with the isolate 15AB-01

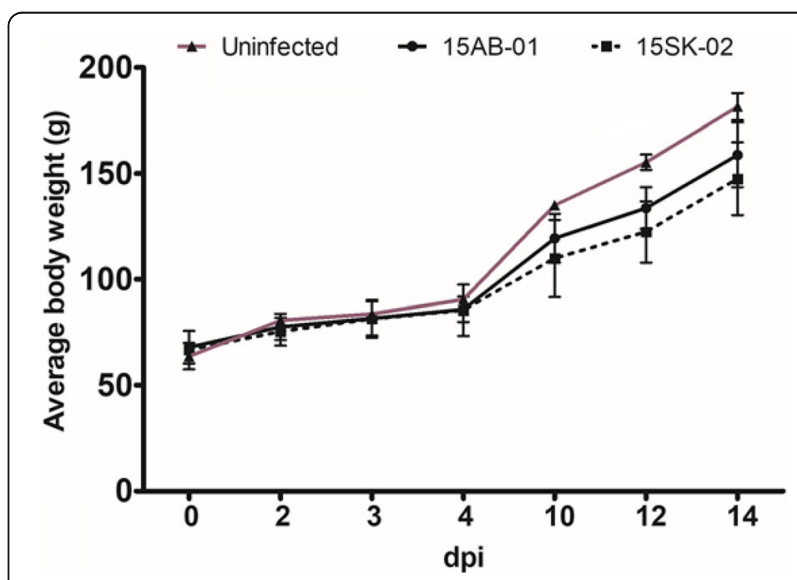

Fig. 3 Bodyweight changes following infection with Western Canadian Mass-type IBV isolates. The average body weight of each group (IBV 15AB-01, IBV 15SK-02 and uninfected control) of chickens at different time points are depicted in the graph. The error bars represent the \pm standard error of mean (SEM) 

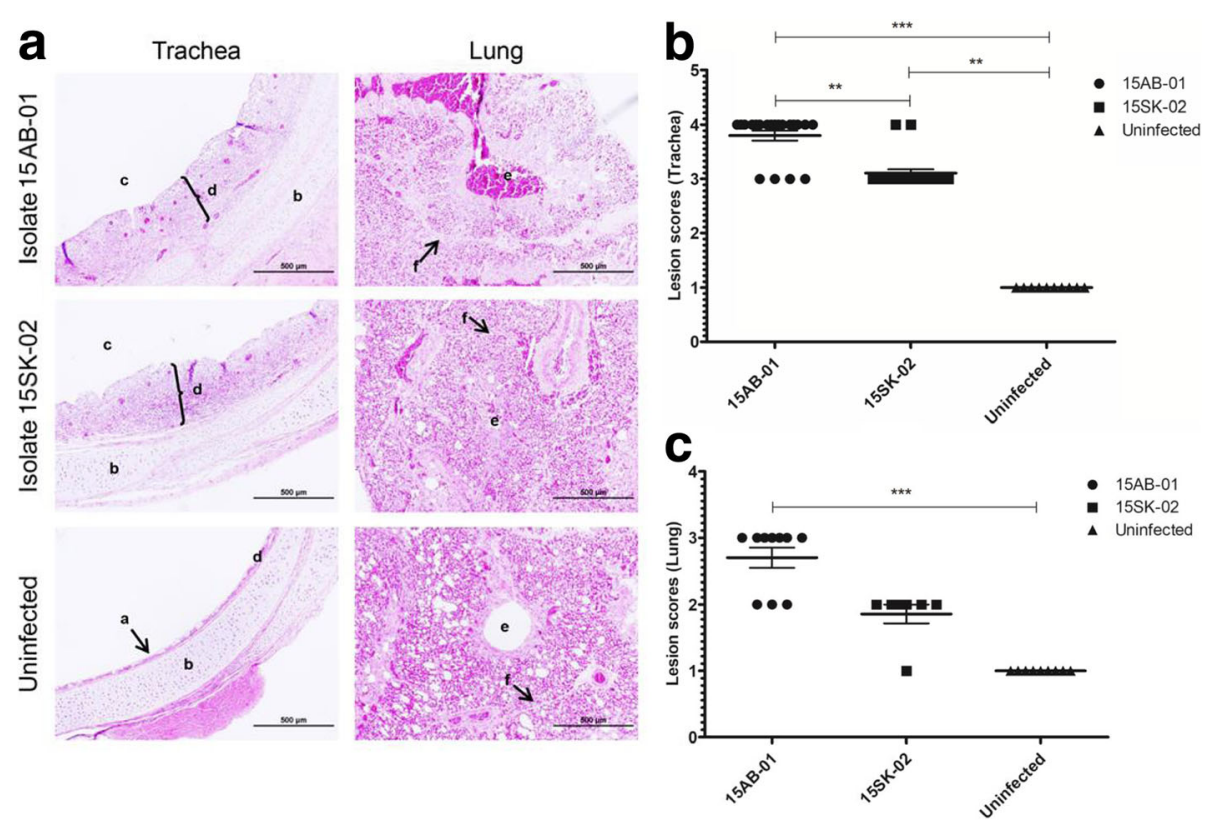

Fig. 4 Histological changes in trachea and lungs induced by Western Canadian Mass-type IBV isolates. The representative images of trachea and lungs (a) and average lesion scores of trachea (b) and lung (c) for each group of chickens (IBV 15AB-01, IBV 15SK-02 and uninfected control) at 4 dpi are depicted. $a=$ cilia, $b=$ tracheal cartilage, $c=$ tracheal lumen, $d=$ tracheal mucosa, $e=$ parabronchial lumen and $f=$ inter-parabronchial septum. The error bars represent the \pm SEM. Statistical significance: ${ }^{*} p<0.05,{ }^{* *} p<0.01,{ }^{* *} p<0.001$
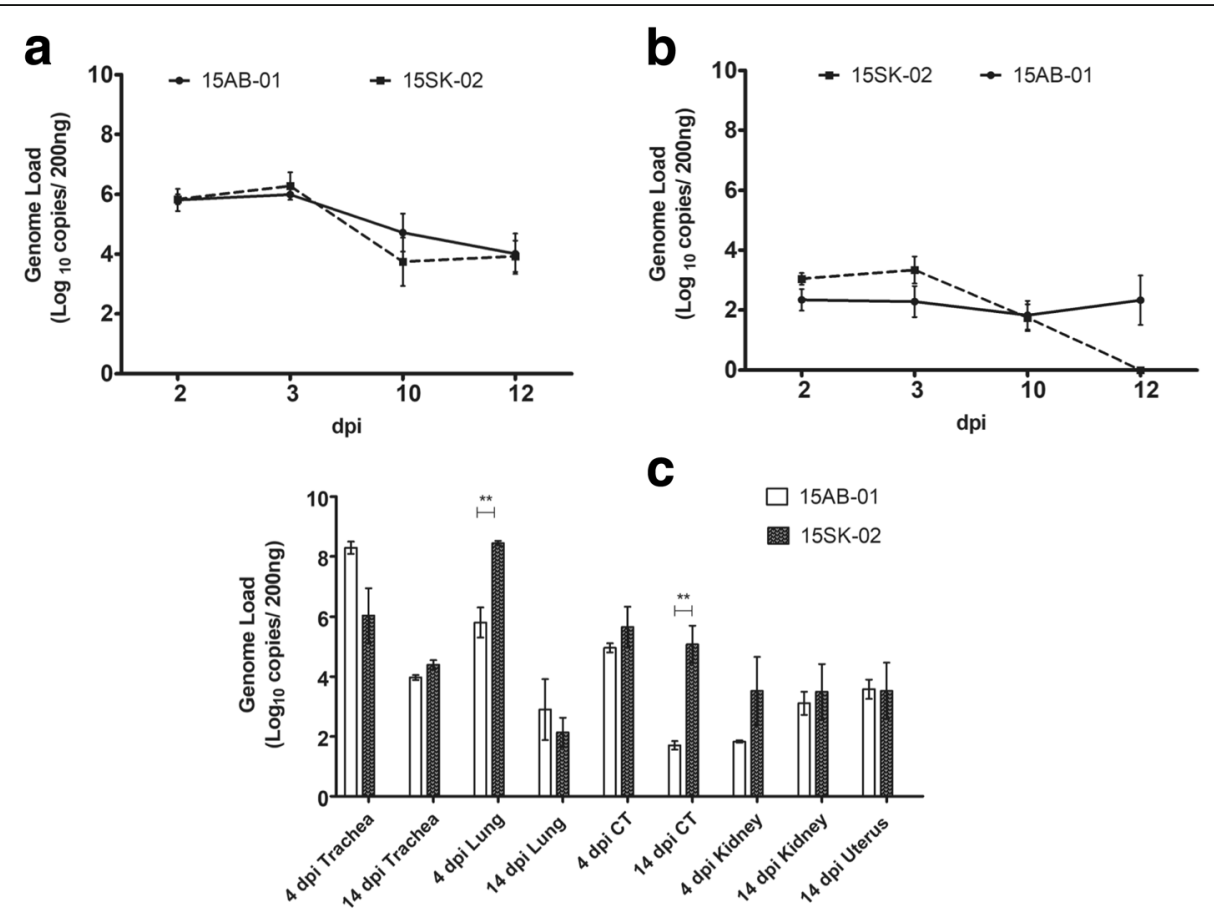

Fig. 5 IBV genome loads in swabs and tissues following infection with Western Canadian Mass-type IBV isolates. For each time point, the average $\log _{10}$ starting IBV copies per $200 \mathrm{ng}$ of extracted RNA from the oropharyngeal (a) and cloacal (b) swabs and various tissues (c) at 4 and 14 dpi are shown with the SEM. Statistical significance: ${ }^{*} p<0.05,{ }^{* *} p<0.01,{ }^{* *} p<0.001$ 
and the difference was statistically significant $(p<0.01)$. There was no difference in genome loads in the kidney tissue between two time points in both strains. The uterine genome loads were available only at $14 \mathrm{dpi}$ for both strains. None of the uninfected control birds had detectable IBV genome loads (results not shown).

\section{Immunofluorescence data for IBV antigens and macrophages at $4 \mathrm{dpi}$}

Similar to IBV genome loads, we did not see a difference in IBV antigen expression in trachea of 15AB-01 and 15SK-02 infected chickens ( $p>0.05$, Fig. $6 \mathrm{~b})$. Similar to the IBV genome load, the amount of IBV antigen was significantly lower in 15AB-01 infected lung than that of 15SK-02 infected lung ( $p<0.01$, Fig. $7 \mathrm{~b}$ ). The lung and tracheal macrophage numbers were not significantly different in the two groups of experimentally infected chicken, indicating a similar response to the two strains of Mass IBV used in the study $(p>0.05)$. Macrophage infiltration was significantly higher $(p<0.05)$ in tracheas infected with both Mass IBV isolates compared to the tracheas of uninfected controls (Fig. 6a and c). Similarly, lungs infected with either Mass IBV isolates had significantly higher number of macrophages $(p<0.01)$ than lungs from uninfected controls (Fig. 7a and c). In both the trachea and lung, there was no significant difference in IBV positive macrophages between two Mass IBV isolates (Figs. 6d and 7d).

\section{Discussion}

The work described in this manuscript focused, first, to see the genetic differences of two Mass variant IBV isolates originating from layer flocks in two provinces of Western Canada. Second, we evaluated if infection of SPF chicken with genetically different Mass IBV variants would result in a different pathogenicity, tissue distribution and macrophage responses in the respiratory tract. Since the S1 protein is the main inducer of virus-neutralizing antibodies [52-54], either partial [31-33] or full-length [34-39] S1 glycoprotein gene have been used in many studies involving IBV molecular characterization throughout the world including previous Canadian studies. Using whole genome sequencing it has been shown that genes other than S1 may be playing roles in the pathogenicity of IBV $[41,55]$. To our knowledge this is the first study, which investigated the full genome of Canadian IBV isolates. Although, IBV strains circulating in other countries have been characterized and changes in the IBV genome due to mutations and recombination have been shown [40, 55-59], our whole genome sequencing data shows that mutations are more common than the recombination and genes other than S1 have been affected by mutations. These changes in the genome of these two IBV isolates reflected in the differences in the pathogenicity although host response characterized by macrophage recruitment into the respiratory tract were similar.
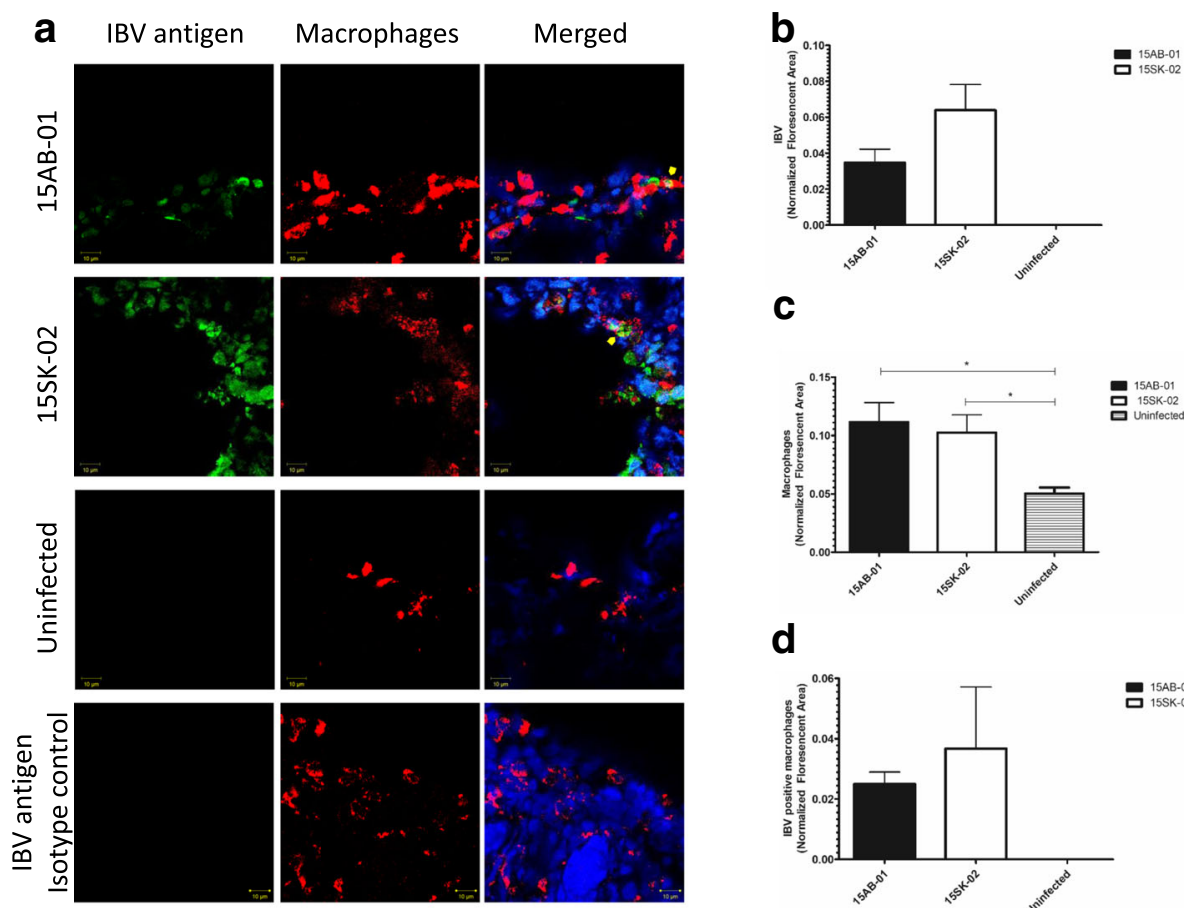

C

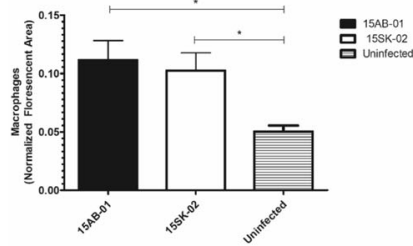

d

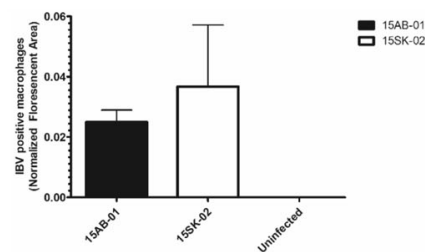

Fig. 6 Mass-type IBV isolates recovered from Western Canadian layer flocks increase macrophage numbers in trachea. The representative images of trachea stained for IBV antigens and macrophages (a) and quantitative data for IBV antigens (b), macrophages (c) and IBV antigen positive macrophages (d) at $4 \mathrm{dpi}$ are depicted. The error bars represent the \pm SEM. Statistical significance: ${ }^{*} p<0.05,{ }^{* *} p<0.01,{ }^{* * *} p<0.001$ 


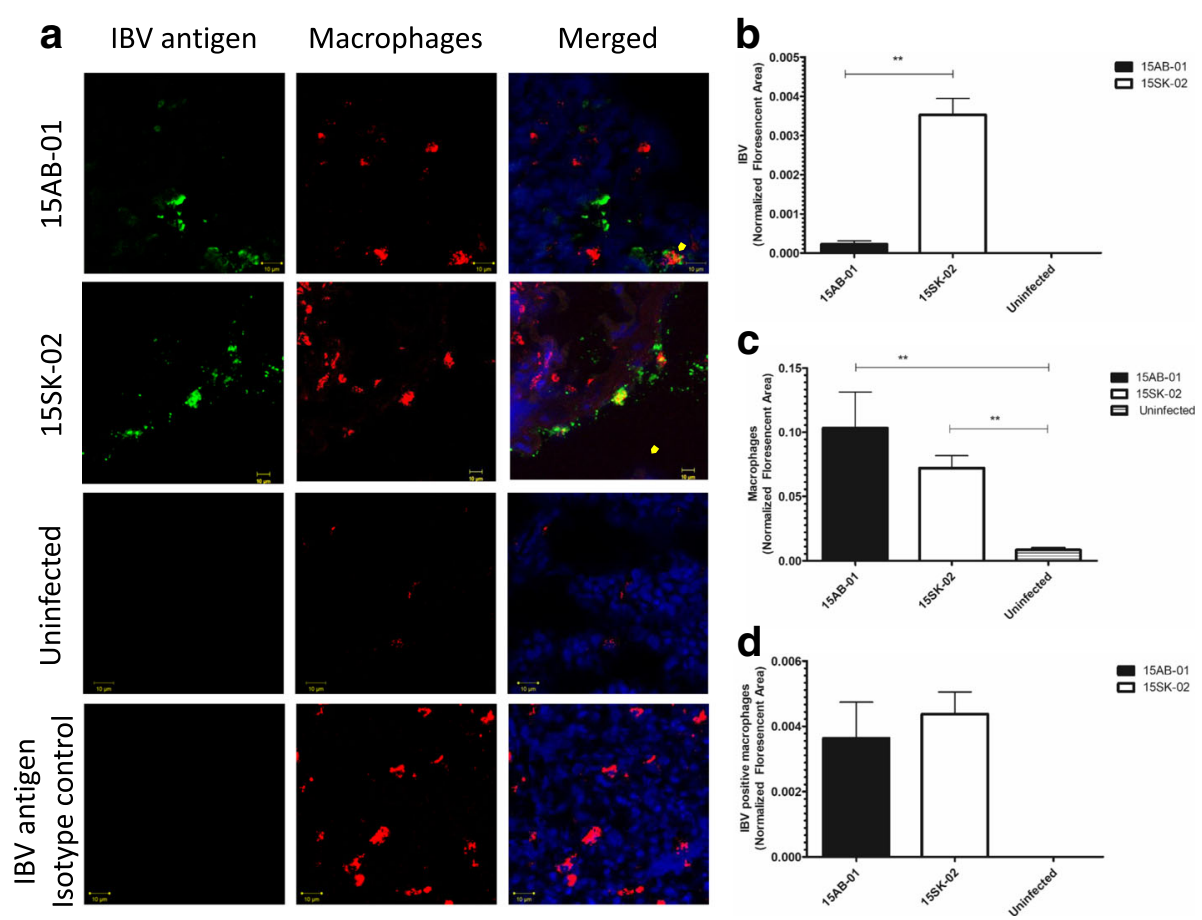

Fig. 7 Mass-type IBV isolates recovered from Western Canadian layer flocks increase macrophage numbers in lungs. The representative images of lungs stained for IBV antigens and macrophages (a) and quantitative data for IBV antigens (b), macrophages (c) and IBV antigen positive macrophages (d) at 4 dpi are depicted. The error bars represent the \pm SEM. Statistical significance: ${ }^{*} p<0.05,{ }^{* *} p<0.01,{ }^{* * *} p<0.001$

Previously, studies have been conducted to compare pathogenicity and immune responses between nephropathogenic (i.e. QX like IBV strains) and Mass type IBV isolates recovered from various geographical areas $[18$, 42, 43, 45, 46]. Nephropathogenic QX-type strains are distantly related to the M41 strain and their genetic similarity is $78.6 \%$ [60]. Based on the partial S1 sequence analysis of three nephropathogenic IBV isolates, which belong to the Mass genotype revealed that they are more than 99.1 and $97.8 \%$ identical to the classical M41 strain in nucleotide and deduced amino acid sequences, respectively [61]. Since it is well known that very minor changes in the genome of viruses [47] including IBV $[49,62]$ lead to differences in pathogenicity and host responses, we chose two Mass type IBV isolates expected to have minor genome differences for evaluation of pathogenicity, tissue distribution and host responses. Mass type IBV isolates have been shown to replicate in the respiratory tissues, kidney, cecal tonsils and gastrointestinal tissues [18, 42, 43]. In agreement with these studies, we also observed that Mass IBV isolates originating from Western Canadian layer flocks replicate in tissues other than respiratory tissues. In our study, Mass IBV isolate originating in SK had significantly higher genome load in the lungs than the one originating in $A B$, though there was no difference of lung lesion score between these two IBV isolates. On the other hand, in trachea, the genome loads of these two Mass IBV isolates were not different, although the Mass IBV isolate originated in $A B$ had significantly higher lesion scores. It is also noteworthy that Mass IBV isolate originating in SK was not detectable at $12 \mathrm{dpi}$ in cloacal swabs. Since the major source of IBV genome in cloaca is due to IBV replication in gastrointestinal tract [63], it is possible that 15SK-02 IBV infection in gastrointestinal tract may have been cleared by $12 \mathrm{dpi}$. Overall, these two Mass IBV variants have similar pathogenicity with only slight differences which also agree with the minor genetic differences of these 2 Mass type IBV isolates.

Literature that describe pathogenicity using Canadian IBV isolates are scarce [8] Although this study evaluated the pathogenicity of 5 IBV isolates originated in Ontario poultry flocks, IBV shedding, tissue distribution and macrophage response have not been studied. Molecular characterization of IBV strains circulating in Canada has been done previously and it appears that there is a difference in distribution of IBV genotypes according to the geographic area within Canada [33, 37, 50, 51]. In Western Canada, mostly Mass and Conn IBV genotypes are common and in Eastern Canada, in addition to Mass and Conn genotypes nepharopathogenic strains, 4/91, CA1737 and DMV genotypes are common among poultry flocks. 
It appears that host responses, characterized by respiratory macrophages following IBV infection is dependent on the IBV strain. For example, it has been shown that M41 but not Australian T strain increases macrophages in respiratory tract lavage [64]. Previously, it has also been shown that IBV ConnA5968 strain elicit higher macrophage response in tracheal mucosa when compared IBV M41 strain [65]. Although Mass IBV (M41) strain is known to increase macrophage responses in lungs and trachea [65], it is unknown whether variants of Mass IBV are capable of eliciting differential macrophage response in the respiratory mucosa. The current study shows that minor genetic differences in Mass IBV variants do not lead to differences in macrophage responses in the respiratory tract although each of the tested IBV isolates were able to elicit significant macrophage responses in these tissues. IBV M41 and ConnA5968 strains have been shown to replicate in macrophages in vivo and in vitro [65-67]. The IBV Beaudette strain is able to infect the HD11 macrophage cell line [68]. Although we did not observe a difference in macrophage infection in vivo by both Mass variant IBV isolates used in our experiments, it will be important to establish if these field IBV strains also target macrophages located in the respiratory tract for its replication. We observed a higher quantity of IBV antigens in 15SK-02 IBV infected lungs when compared to 15AB-01 infected lungs and that difference was not reflected in the number of IBV infected macrophages. This discrepancy may be due to the fact that IBV infects cells other than macrophages. Previously, we observed that IBV infection in macrophage of the respiratory tract was about $3-4 \%$ [65].

In spite of the novel aspect of our work comparing two Mass type IBV isolates with minor genetic variations for pathogenicity and host responses, there were some limitations to this study. First, we did not include a control group infected with the standard M41 IBV strain in our experiment and this was due to the limited infrastructure availability at our animal facility. However, in a separate study, we investigated the M41 IBV induced macrophage recruitment to respiratory tract [65]. Second, for the quantification of IBV, we employed real-time PCR technique targeting the most conserved N gene of IBV [69-71]. Since qPCR quantify both live and dead virus [72], our IBV genome load data do not reflect IBV replication. Alternatively, we would have determined viral titers using 9-11 day old SPF embryonated chicken eggs and expressed as EID $_{50}$ [73]. Although this later method could be employed to determine IBV infectivity in our swabs and tissues, the use of this technique was precluded for quantifying IBV titer due to the requirement of large numbre of eggs.

\section{Conclusion}

In conclusion, Mass IBV variants recovered from layer flocks had identical nucleotide sequence at ORFs $3 \mathrm{a}, 3 \mathrm{~b}$, $\mathrm{E}, \mathrm{M}, 5 \mathrm{a}$ and $5 \mathrm{~b}$. The remainder of the ORFs showed 99.9\% nucleotide similarity. Although, the genetic changes were minor, the pathogenicity in vivo of the Mass IBV variant originating from $\mathrm{AB}$ was different to the one that originated in $S K$, whereby the $A B$ variant caused significantly higher tracheal lesions and replicated to a lower titer in the lung and lower genome loads in cecal tonsils. Additionally, both Mass IBV variants elicited host responses characterized by significant macrophage recruitment to the respiratory tract and there was evidence that both Mass IBV variants replicated within macrophages in the respiratory tract. Studies are underway to evaluate the pathogenicity of these two Mass type IBV isolates in laying hens.

\section{Methods \\ Animals}

Day old white leghorn (SPF) layer chickens (White Leghorn) were obtained from the Canadian Food Inspection Agency (CFIA), Ottawa, ON, Canada and housed in high containment poultry isolators at the Prion- Virology Animal Facility of the University of Calgary's Foothills Campus with ad libitum access to feed and water.

\section{Virus}

Mass IBV isolates originating from layer flocks in $A B$ (15AB-01) and SK (15SK-02) were used in the study. Viral titers were determined using 9-day old SPF embryonated chicken eggs and expressed as 50\% embryo infectious dose $\left(\mathrm{EID}_{50}\right)$ according to the method described by Reed and Muench [73].

\section{Experimental design \\ Whole genome sequencing of mass IBV isolates that originated from Western Canada}

The Mass-type IBV isolates from the current study were sequentially passaged in 9 to 11-day old embryonated eggs and allantoic fluid was harvested and concentrated using ultracentrifugation at $50,000 \mathrm{~g}$ for $3 \mathrm{~h}$. The resulting pellet was fractionated using the Optiprep ${ }^{\text {тx }}$ kit (Millipore-Sigma, Missouri, USA). Ribonucleic acid (RNA) was extracted from the sixth fraction and allantoic fluid directly. cDNA was synthesized, and quantitative polymerase chain reaction (PCR) assay was performed to quantify the IBV genome load.

\section{Infection of chickens with mass IBV isolates originated from Western Canada}

Two groups of 6 day-old unsexed-SPF chickens $(n=7$ per group) were infected with $50 \mu \mathrm{L}$ inoculum containing $2.75 \times 10^{4}$ PFUs of IBV isolates 15AB-01 and 15SK-02 
intra-tracheally under isoflurane anesthesia. Another 5 of 6-day old SPF chickens were kept as uninfected controls. The chickens were weighed at $0,2,3,4,10,12$ and 14 dpi. At 2, 3, 10 and $12 \mathrm{dpi}$, oropharyngeal and cloacal swabs were obtained using Puritan ${ }^{\bullet}$ Unitranz-RT transport system (Puritan Medical Products LLC, Maine, USA) and stored at $-80^{\circ} \mathrm{C}$ until further processing. At $4 \mathrm{dpi}, 4$ chickens from each infected and 3 chickens from the uninfected group were euthanized and trachea, lung, kidneys, cecal tonsils and reproductive tract samples were collected into RNASave ${ }^{\circ}$ (Biological Industries, Beit Haemek, Israel) and stored at $-20^{\circ} \mathrm{C}$. In addition, a portion of trachea, lung, kidneys, cecal tonsils and reproductive tract samples were collected into $10 \%$ neutral buffered formalin for histopathological examination and in Optimum Cutting Medium (OCT, Leica Biosystems, Wetzlar, Germany) for immunostaining. The remainder of chickens were continued to be observed and tissue samples were collected in RNASave ${ }^{\circ}$ for genome load quantification at $14 \mathrm{dpi}$.

For the sampling of tissues, the chickens were euthanized using overdose of isoflurane anesthesia followed by cervical dislocation.

\section{Techniques}

\section{Sample preparation for whole genome sequencing}

The virus fractions, which gave the highest genome load or the lowest $\mathrm{Ct}$ were selected from both isolates and cDNA concentration was determined using the Qubit 4 Fluorometer (Thermo Fisher Scientific, MA, USA). A total of 10-12 ng of cDNA from each isolate was sent for whole genome sequencing to the Swine and Poultry Infectious Diseases Research Center (CRIPA), University of Montreal, Canada where library preparation and sequencing performed on Illumina ${ }^{\circ}$ Miseq (San Diego, California, United States) next generation sequencing (NGS) platform generating $150 \mathrm{bp}$ paired-end reads.

\section{Histology}

Formalin-fixed terminal tissue samples were processed at the Diagnostic Services Unit of the University of Calgary's Faculty of Veterinary Medicine including staining of sections with stained hematoxylin and eosin (H\&E). Sections were examined under the light microscope and photomicrographs were taken under 40x magnification. The histological changes observed in the trachea [8] and lungs [69] were scored as described previously.

\section{RNA extraction and CDNA synthesis}

Tracheal and cloacal swab samples, which were in the transport media were vortexed and medium was transferred to $1.5 \mathrm{~mL}$ centrifuge tubes and centrifuged at $1000 \mathrm{~g}$ for $20 \mathrm{mins}$ at $-4{ }^{\circ} \mathrm{C}$. A total of $250 \mu \mathrm{L}$ of supernatant was used for RNA extraction using the Trizol $\mathrm{LS}^{\circ}$ reagent (Ambion, Invitrogen Canada Inc., Burlington, ON, Canada) following manufacturer's instructions. Approximately $50 \mathrm{mg}$ piece of tissue preserved in RNA Save ${ }^{\circ}$ was homogenized in $1 \mathrm{~mL}$ of $\mathrm{Trizol}^{\circ}$ reagent (Ambion, Invitrogen Canada Inc., Burlington, ON, Canada) using a Pro200 Power homogenizer (Diamed, Mississauga, ON, Canada) on ice and RNA was extracted following the manufacturer's protocol. The RNA pellet was re-suspended in $20 \mu \mathrm{L}$ of RNase-free water and quantified using the Nanodrop 1000 spectrophotometer at 260 $\mathrm{nm}$ wavelength (Thermo Scientific, Wilmington, DE, USA). A total of $2000 \mathrm{ng}$ of RNA was transcribed using 10X RT random primers (High Capacity cDNA Reverse Transcription Kit, Invitrogen Life Technologies, Carlsbad, CA, USA) as has been instructed by the manufacturer.

\section{IBV genome load quantification}

The IBV genome load quantification was carried out following the products and protocol as described previously [65]. Briefly, real-time PCR method was used for IBV genome load quantification using forward primer, IBV N Fw: 5'GACGGAGGACCTGATGGTAA3' and reverse primer, IBV-N Re: 5'CCCTTCTTCTGCTG ATCCTG3'. Thermal cycling conditions were $95^{\circ} \mathrm{C}$ for $20 \mathrm{~s} ; 40$ cycles of amplification/extension at $95^{\circ} \mathrm{C}$ for $3 \mathrm{~s}$, and $60^{\circ} \mathrm{C}$ for $30 \mathrm{~s}$ followed by a melting curve analysis was done between $65^{\circ} \mathrm{C}$ to $95^{\circ} \mathrm{C}$ with an increment of $0.5^{\circ} \mathrm{C}$ at every $5 \mathrm{~s}$. Fluorescent acquisition was done at $60^{\circ} \mathrm{C}$ for $30 \mathrm{~s}$.

\section{Immunofluorescent assay}

Frozen tissues in OCT blocks were sectioned at $5 \mu \mathrm{m}$ thickness using a cryotome (Leica Biosystems, Richmond, Illinois, USA) and adhered on to positively charged slides. The sections were air dried on the bench for $20 \mathrm{~min}$, fixed by immersing in ice-cold acetone for $5 \mathrm{~min}$ and stained for macrophage and IBV antigens sequentially as has been described previously [65]. Briefly, after protein blocking with $2.5 \%$ horse serum, the cryosections were incubated for $30 \mathrm{~min}$ with mouse monoclonal anti-chicken macrophage (KUL01) antibodies (Southern Biotech, Birmingham, Alabama, USA) (1:200 in PBS containing 2.5\% horse serum). The staining specificity of KUL01 anti-chicken macrophage antibody was confirmed previously using an appropriate isotype control (Additional file 1: Figure 1). The secondary antibody, DyLight 550 conjugated goat anti-mouse IgG ( $\mathrm{H}+\mathrm{L})$ (Vector Laboratories, Inc., Burlingame, California, USA) (1:500 in PBS containing $2.5 \%$ horse serum) was used. Before being stained for IBV antigen using anti-IBV rabbit polyclonal serum (Federal Research Institute for Animal Health, Greifswald-Insel Riems, Germany; 1:3000 diluted in $2.5 \%$ horse serum), the sections were blocked again with $2.5 \%$ of horse serum. For subsequent staining, 
Vectaflour RTU Antibody kit containing Dylight 488 conjugate (DK-1488, Vector Laboratories, Burlingame, California, USA). The sections were mounted on Vectashield ${ }^{\circ}$ antifade mounting medium with 4',6-Diamidine-2'-phenylindole dihydrochloride (DAPI) nuclear stain (Vector Laboratories, Burlingame, California, USA).

\section{Data analyses}

\section{Whole genome sequencing data analysis}

All reads were assembled to get a single contig. The resulting full genome sequences were aligned, and identity matrix was performed with 43 published sequences of IBV reference serotypes retrieved from the National Center for Biotechnology Information (NCBI) GenBank database using the $\mathrm{BLAST}^{\circ}$ research tool and the Custal Omega 1.2.3 package with automated settings (Geneious $^{\circ}$ 10.1.3). The phylogenetic tree inferred based on the full-length IBV genomes using Randomized Axelerated Maximum Likelihood (RAxML 8.2.7) method with GTR GAMMA nucleotide substitution model with 1000 bootstrap iterations (Geneious software, version 10.1.3, Biomatters Ltd., Auckland, New Zealand). The resulting proportional tree of the two Mass IBV isolates of this study with 43 reference sequences (Additional file 2: Table S1) is shown with the bootstrap support. Nucleotide sequences of the two Mass IBV isolates, 15AB-01 and 15SK-02 were deposited in the NCBI GenBank public domain under the accession numbers MH539771 and MH539772, respectively. ORFs of the two new sequences were determined using the NCBI ORF finder (https://www.ncbi.nlm.nih.gov/orffinder/) and the genome annotation was carried out using Geneious software, version 10.1.3 (Biomatters Ltd., Auckland, New Zealand).

\section{IBV genome load quantification}

IBV genome copies per 200 ng of cDNA were calculated using a standard curve based on a serial dilution of plasmids as described previously [69].

\section{Quantification of the number of macrophages, IBV antigen and IBV positive macrophages}

For the quantification of macrophages and the IBV antigen in the trachea and lungs, five areas with the highest DyLight $^{\circ} 550$ (macrophages) and DyLight ${ }^{\circ} 488$ (IBV antigen) fluorescent signals and corresponding nuclear stained (DAPI) areas were captured under 40x magnification using an epifluorescent microscope (Olympus IX51, Center Valley, Pensylvania, USA). The obtained images were transferred to the Image- $\mathrm{J}^{\circ}$ software (National Institute of Health, Bethesda, Maryland, USA) and the areas of each micrograph covered with DyLight ${ }^{\circ}$ 550 (macrophages), DyLight ${ }^{\circ} 488$ (IBV) signals, combined DyLight $^{\circ} 550$ and DyLight 488 signals (IBV positive macrophages) and the combined DyLight ${ }^{\circ} 550$ and DyLight ${ }^{\circ}$
488 signals with DAPI (total area of the section) were quantified. The areas covered with macrophage and IBV antigens and the combined signals were expressed as a percentage of the total area covered by the section.

\section{Statistical analyses}

Two-way analysis of variance (ANOVA) followed by Benferroni post-hoc test was used to determine the significant time points of body weight among the infected and control groups. Tracheal and lung histopathological lesion score data was analyzed using Kruskal-Wallis test followed by Dunn's multiple comparison test. The genome load data was analyzed by the two-way ANOVA followed by Bonferroni post-test. One-way ANOVA test followed by Tukey's posttest was used to determine the significance of immunofluorescence data. Grubbs' outlier test was performed in order to identify outliers before the data was analyzed. All the statistical procedures were performed using in-built statistical analysis feature of the GraphPad ${ }^{\mathrm{Tm}}$ Prism 5 (GraphPad Software, La Jolla, California, USA). Differences were considered significant at $p<0.05$. The significance on graphs are labelled as the following: $" p<0.05$, *** $p<0.01$, **** $p<0.001$, and ${ }^{* * * * *} p<0.0001$.

\section{Additional files}

Additional file 1: Figure S1. Specificity of avian macrophage staining The power point slide contain lung sections stained with anti-chicken macrophage antibody (KUL-01) and isotype control. The sections were also stained with nuclear staining (DAPI). (DOCX $271 \mathrm{~kb})$.

Additional file 2: Table S1. List of reference IBV sequences used in this study. This table contain names and accession numbers of IBV whole genome reference sequences retrieved from the GenBank repository. (DOCX $15 \mathrm{~kb})$.

\section{Acknowledgements}

We acknowledge the staff involved in field poultry veterinary services in SK and $A B$, Canada. We acknowledge the staff of Prion-Virology Animal Facility, University of Calgary for routine monitoring of experimental animals.

\section{Funding}

This research including graduate student stipend was funded by the SK Agricultural Development Fund and SK Egg Producers (Project number: 20140185). Graduate student, AA was also supported partly by University of Calgary's Eyes-High International Doctoral Scholarship and Bridge Funding from the Department of Ecosystem and Public Health. These funding bodies were not involved in the design of the study, collection, analysis, interpretation of data and in writing the manuscript.

\section{Availability of data and materials}

Nucleotide sequences of the two Mass IBV isolates, 15AB-01 and 15SK-02 is available in the NCBI GenBank public domain under the accession numbers, MH539771 and MH539772, respectively. The remainder of datasets used during the current study are available from the corresponding author on request.

\section{Authors' contributions}

Conceptualization, funding acquisition and project administration was done by SG and MFA. Investigations, data collection and formal analysis were undertaken by AA, UDSS and MSA. SP, FM and Saskatchewan Poultry Extension (Tennille Knezacek, Jenny Fricke and Stephanie Derbawka) 
helped in sample collection leading to the isolation of Mass IBV isolates. Original draft was prepared by AA. Review of the manuscript including editing and student supervision and mentoring were done by SG, SCC, FvdM and MFA. All authors read and approved the final manuscript.

\section{Authors' information}

AA: PhD student, University of Calgary.

UDSS: MSC student, University of Calgary

MSA: PhD student, University of Calgary.

SP: Research Technician-Poultry, University of Saskatchewan.

FM: Veterinarian, Marshall Swine and Poultry Health Services.

SCC: Professor and Head, Ecosystem and Public Health, University of Calgary. FvdM: Associate Professor (Global Health), University of Calgary.

SG: Professor and Head, Department of Veterinary Pathology, University of Saskatchewan.

MFA: Associate Professor (Virology), University of Calgary.

\section{Ethics approval}

The HSACC of the University of Calgary approved the use of SPF chickens used in all our experimental procedures (Protocol number AC15-0140).

\section{Consent for publication}

Not applicable

\section{Competing interests}

The authors declare that they have no competing interests.

\section{Publisher's Note}

Springer Nature remains neutral with regard to jurisdictional claims in published maps and institutional affiliations.

\section{Author details}

'Department of Ecosystem and Public Health, Faculty of Veterinary Medicine, University of Calgary, Health Research Innovation Center 2C53, 3330 Hospital Drive NW, Calgary, AB T2N 4N1, Canada. ${ }^{2}$ Department of Veterinary Pathology, Western College of Veterinary Medicine, University of Saskatchewan, Saskatoon, SK S7N 5B5, Canada. ${ }^{3}$ Marshall Swine and Poultry Health Services, 3831- Bay G- 44 Ave, Camrose, AB T4V 3T1, Canada.

Received: 9 July 2018 Accepted: 27 November 2018

Published online: 10 December 2018

\section{References}

1. Cavanagh D. Coronaviruses in poultry and other birds. Avian Pathology. 2005;34(6):439-48.

2. Cavanagh D. Coronavirus avian infectious bronchitis virus. Vet Res. 2007; 38(2):281-97.

3. Cumming RB. The control of avian infectious bronchitis/nephrosis in Australia Aust Vet J. 1969;45(4):200-3.

4. Kingham BF, Keeler CL, Nix WA, Ladman BS, Gelb J. Identification of avian infectious bronchitis virus by direct automated cycle sequencing of the S-1 gene. Avian Dis. 2000;44(2):325-35.

5. Song C-S, Lee $Y-J$, Lee C-W, Sung H-W, Kim J-H, Mo I-P, Izumiya Y, Jang H-K, Mikami T. Induction of protective immunity in chickens vaccinated with infectious bronchitis virus $\mathrm{S1}$ glycoprotein expressed by a recombinant baculovirus. J Gen Virol. 1998;79(4):719-23.

6. Liu S, Chen J, Han Z, Zhang Q, Shao Y, Kong X, Tong G. Infectious bronchitis virus: S1 gene characteristics of vaccines used in China and efficacy of vaccination against heterologous strains from China. Avian Pathology. 2006; 35(5):394-9.

7. Reddy VRAP, Theuns S, Roukaerts IDM, Zeller M, Matthijnssens J, Nauwynck HJ. Genetic characterization of the Belgian Nephropathogenic infectious bronchitis virus (NIBV) reference strain B1648. Viruses. 2015;7(8):4488-506.

8. Grgic H, Hunter DB, Hunton P, Nagy E. Pathogenicity of infectious bronchitis virus isolates from Ontario chickens. Can J Vet Res. 2008;72(5):403-10.

9. Boroomand Z, Asasi K, Mohammadi A. Pathogenesis and tissue distribution of avian infectious bronchitis virus isolate IRFIBV32 (793/B serotype) in experimentally infected broiler chickens. Sci World J. 2012;2012:402537.

10. Franca M, Woolcock PR, Yu M, Jackwood MW, Shivaprasad HL. Nephritis associated with infectious bronchitis virus Cal99 variant in game chickens. Avian Dis. 2011;55(3):422-8.
11. Ambali AG, Jones RC. Early pathogenesis in chicks of infection with an Enterotropic strain of infectious bronchitis virus. Avian Dis. 1990;34(4):809-17.

12. El-Houadfi M, Jones RC, Cook JKA, Ambali AG. The isolation and characterisation of six avian infectious bronchitis viruses isolated in Morocco. Avian Pathology. 1986;15(1):93-105.

13. Sevoian M, Levine P. Effects of infectious bronchitis on the reproductive tracts, egg production, and egg quality of laying chickens. Avian Dis. 1957;1(2):136-64

14. MacDonald JW, McMartin DA. Observations on the effects of the h52 and h120 vaccine strains of infectious bronchitis virus in the domestic fowl. Avian Pathology. 1976;5(3):157-73.

15. Raj GD, Jones RC. Infectious bronchitis virus: Immunopathogenesis of infection in the chicken. Avian Pathology. 1997;26:677-706.

16. Cook JK, Jackwood M, Jones RC. The long view: 40 years of infectious bronchitis research. Avian Pathology. 2012;41(3):239-50.

17. Crinion RAP, Ball RA, Hofstad MS. Abnormalities in laying chickens following exposure to infectious bronchitis virus at one day old. Avian Dis. 1971;15(1):42-8.

18. Benyeda Z, Mato T, Suveges T, Szabo E, Kardi V, Abonyi-Toth Z, Rusvai M, Palya V. Comparison of the pathogenicity of QX-like, M41 and 793/B infectious bronchitis strains from different pathological conditions. Avian Pathology. 2009;38(6):449-56.

19. Boltz DA, Nakai M, Bahra JM. Avian infectious bronchitis virus: a possible cause of reduced fertility in the rooster. Avian Dis. 2004;48(4):909-15.

20. Liu S, Zhang X, Wang Y, Li C, Han Z, Shao Y, Li H, Kong X. Molecular characterization and pathogenicity of infectious bronchitis coronaviruses: complicated evolution and epidemiology in China caused by Cocirculation of multiple types of infectious bronchitis coronaviruses. Intervirology. 2009;52(4):223-34.

21. Alvarado IR, Villegas $P$, Mossos N, Jackwood MW. Molecular characterization of avian infectious bronchitis virus strains isolated in Colombia during 2003. Avian Dis. 2005:49(4):494-9.

22. Kusters JG, Niesters HGM, Bleumink-Pluym NMC, Davelaar FG, Horzinek MC, Van der Zeijst BAM. Molecular epidemiology of infectious bronchitis virus in the Netherlands. J Gen Virol. 1987;68(2):343-52.

23. Lee C-W, Jackwood MW. Evidence of genetic diversity generated by recombination among avian coronavirus IBV. Arch Virol. 2000;145(10):2135-48.

24. Kottier SA, Cavanagh D, Britton P. Experimental evidence of recombination in coronavirus infectious bronchitis virus. Virology. 1995;213(2):569-80.

25. Wang $L, X u Y$, Collisson EW. Experimental confirmation of recombination upstream of the $\mathrm{S} 1$ hypervariable region of infectious bronchitis virus. Virus Res. 1997:49(2):139-45.

26. Mardani K, Noormohammadi A, Ignjatovic J, Browning G. Naturally occurring recombination between distant strains of infectious bronchitis virus. Arch Virol. 2010;155(10):1581-6

27. Jia W, Karaca K, Parrish CR, Naqi SA. A novel variant of avian infectious bronchitis virus resulting from recombination among three different strains. Arch Virol. 1995;140(2):259-71.

28. Montassier HJ. Molecular epidemiology and evolution of avian infectious bronchitis virus. Revista Brasileira de Ciência Avícola. 2010;12:87-96.

29. Cavanagh D, Davis PJ, Darbyshire JH, Peters RW. Coronavirus IBV: virus retaining spike glycopolypeptide $\mathrm{S} 2$ but not $\mathrm{S} 1$ is unable to induce virusneutralizing or haemagglutination-inhibiting antibody, or induce chicken tracheal protection. J Gen Virol. 1986;67(7):1435-42.

30. Cavanagh D, Davis PJ, Cook JKA. Infectious bronchitis virus: evidence for recombination within the Massachusetts serotype. Avian Pathology. 1992; 21(3):401-8.

31. Selim K, Arafa AS, Hussein HA, El-Sanousi AA. Molecular characterization of infectious bronchitis viruses isolated from broiler and layer chicken farms in Egypt during 2012. International Journal of Veterinary Science and Medicine. 2013;1(2):102-8

32. Awad F, Baylis M, Ganapathy K. Detection of variant infectious bronchitis viruses in broiler flocks in Libya. International Journal of Veterinary Science and Medicine. 2014;2(1):78-82

33. Martin EA, Brash ML, Hoyland SK, Coventry JM, Sandrock C, Guerin MT, Ojkic D. Genotyping of infectious bronchitis viruses identified in Canada between 2000 and 2013. Avian Pathology. 2014;43(3):264-8.

34. Jackwood MW, Lee DH. Different evolutionary trajectories of vaccine-controlled and non-controlled avian infectious bronchitis viruses in commercial poultry. PLoS One. 2017:12(5):e0176709.

35. Hong S-M, Kwon H-J, Kim I-H, Mo M-L, Kim J-H. Comparative genomics of Korean infectious bronchitis viruses (IBV/s) and an animal model to evaluate pathogenicity of IBVs to the reproductive organs. Viruses. 2012;4(11):2670. 
36. Marandino A, Pereda A, Tomas G, Hernandez M, Iraola G, Craig MI Hernandez D, Banda A, Villegas P, Panzera Y, et al. Phylodynamic analysis of avian infectious bronchitis virus in South America. The Journal of General Virology. 2015;96(Pt 6):1340-6.

37. Smati R, Silim A, Guertin C, Henrichon M, Marandi M, Arella M, Merzouki A Molecular characterization of three new avian infectious bronchitis virus (IBV) strains isolated in Quebec. Virus Genes. 2002;25(1):85-93.

38. Feng K, Wang F, Xue Y, Zhou Q, Chen F, Bi Y, Xie Q. Epidemiology and characterization of avian infectious bronchitis virus strains circulating in southern China during the period from 2013-2015. Sci Rep. 2017;7(1):6576

39. Mo ML, Li M, Huang BC, Fan WS, Wei P, Wei TC, Cheng QY, Wei ZJ, Lang $\mathrm{YH}$. Molecular characterization of major structural protein genes of avian coronavirus infectious bronchitis virus isolates in southern China. Viruses. 2013;5(12):3007-20.

40. Quinteros JA, Markham PF, Lee SW, Hewson KA, Hartley CA, Legione AR, Coppo MJ, Vaz PK, Browning GF. Analysis of the complete genomic sequences of two virus subpopulations of the Australian infectious bronchitis virus vaccine VicS. Avian Pathology. 44(3):182-91.

41. van Beurden SJ, Berends AJ, Kramer-Kuhl A, Spekreijse D, Chenard G, Philipp HC, Mundt E, Rottier PJM, Verheije MH. Recombinant live attenuated avian coronavirus vaccines with deletions in the accessory genes $3 a b$ and/or $5 a b$ protect against infectious bronchitis in chickens. Vaccine. 2018;36(8):1085-92.

42. Benyeda Z, Szeredi L, Mató T, Süveges T, Balka G, Abonyi-Tóth Z, Rusvai M, Palya V. Comparative histopathology and immunohistochemistry of QX-like, Massachusetts and 793/B serotypes of infectious bronchitis virus infection in chickens. J Comp Pathol. 2010;143(4):276-83.

43. W-q F, H-n W, Zhang Y, Z-b G, Wang T, C-w X, A-y Z, Yang X. Comparative dynamic distribution of avian infectious bronchitis virus M41, H120, and SAIBK strains by quantitative real-time RT-PCR in SPF chickens. Biosci Biotechnol Biochem. 2012;76(12):2255-60.

44. Cheng J, Huo C, Zhao J, Liu T, Li X, Yan S, Wang Z, Hu Y, Zhang G. Pathogenicity differences between QX-like and mass-type infectious bronchitis viruses. Vet Microbiol. 2018;213:129-35.

45. Chhabra R, Kuchipudi SV, Chantrey J, Ganapathy K. Pathogenicity and tissue tropism of infectious bronchitis virus is associated with elevated apoptosis and innate immune responses. Virology. 2016:488:232-41.

46. Chhabra R, Ball C, Chantrey J, Ganapathy K. Differential innate immune responses induced by classical and variant infectious bronchitis viruses in specific pathogen free chicks. Developmental \& Comparative Immunology. 2018;87:16-23.

47. Bae JY, Lee I, Kim Jl, Park S, Yoo K, Park M, Kim G, Park MS, Lee JY, Kang C, et al. A single amino acid in the polymerase acidic protein determines the pathogenicity of influenza B viruses. J Virol. 2018;92(13):e00259-18.

48. Cavanagh D, Davis PJ, Cook JK, Li D, Kant A, Koch G. Location of the amino acid differences in the $\mathrm{S} 1$ spike glycoprotein subunit of closely related serotypes of infectious bronchitis virus. Avian Pathology. 1992;21(1):33-43.

49. Binns MM, Boursnell ME, Tomley FM, Brown DK. Comparison of the spike precursor sequences of coronavirus IBV strains M41 and 6/82 with that of IBV Beaudette. J Gen Virol. 1986;67(Pt 12):2825-31.

50. Amarasinghe A, Popowich S, De Silva Senapathi U, Abdul-Cader MS, Marshall F, van der Meer F, Cork SC, Gomis S, Abdul-Careem MF. Shellless egg syndrome (SES) widespread in Western Canadian layer operations is linked to a Massachusetts (mass) type infectious bronchitis virus (IBV) isolate. Viruses. 2018;10(8). https://doi.org/10.3390/v10080437.

51. Stachowiak BKD, Hunton P, Gillingham S, Nagy É. Infectious bronchitis virus surveillance in Ontario commercial layer flocks. The Journal of Applied Poultry Research. 2005;14(1):141-6.

52. Ignjatovic J, McWaters PG. Monoclonal antibodies to three structural proteins of avian infectious bronchitis virus: characterization of epitopes and antigenic differentiation of Australian strains. J Gen Virol. 1991;72(12):2915-22.

53. Kant A, Koch G, van Roozelaar DJ, Kusters JG, Poelwijk FAJ, van der Zeijst BAM. Location of antigenic sites defined by neutralizing monoclonal antibodies on the S1 avian infectious bronchitis virus glycopolypeptide. J Gen Virol. 1992;73(3):591-6.

54. Cavanagh D, Davis PJ, Mockett APA. Amino acids within hypervariable region 1 of avian coronavirus IBV (Massachusetts serotype) spike glycoprotein are associated with neutralization epitopes. Virus Res. 1988;11(2):141-50.

55. Quinteros JA, Lee S-W, Markham PF, Noormohammadi AH, Hartley CA Legione AR, Coppo MJC, Vaz PK, Browning GF. Full genome analysis of Australian infectious bronchitis viruses suggests frequent recombination events between vaccine strains and multiple phylogenetically distant avian coronaviruses of unknown origin. Vet Microbiol. 2016;197:27-38.

56. Abozeid HH, Paldurai A, Khattar SK, Afifi MA, El-Kady MF, El-Deeb AH, Samal SK. Complete genome sequences of two avian infectious bronchitis viruses isolated in Egypt: evidence for genetic drift and genetic recombination in the circulating viruses. Infect Genet Evol. 2017;53:7-14.

57. Naguib MM, Höper D, Arafa A-S, Setta AM, Abed M, Monne I, Beer M, Harder TC. Full genome sequence analysis of a newly emerged QX-like infectious bronchitis virus from Sudan reveals distinct spots of recombination. Infect Genet Evol. 2016:46:42-9.

58. Wu X, Yang X, Xu P, Zhou L, Zhang Z, Wang H. Genome sequence and origin analyses of the recombinant novel IBV virulent isolate SAIBK2. Virus Genes. 2016:52(4):509-20.

59. $X-I L, J-I S, J-x Z Z, G-Z Z$. Complete genome sequence analysis of a predominant infectious bronchitis virus (IBV) strain in China. Virus Genes. 2009;38(1):56-65.

60. Khataby K, Souiri A, Kasmi Y, Loutfi C, Ennaji MM. Current situation, genetic relationship and control measures of infectious bronchitis virus variants circulating in African regions. The Journal of Basic \& Applied Zoology. 2016; 76:20-30.

61. Li H, Yang $H$. Sequence analysis of nephropathogenic infectious bronchitis virus strains of the Massachusetts genotype in Beijing. Avian Pathology. 2001;30(5):535-41.

62. Yan S, Liu X, Zhao J, Xu G, Zhao Y, Zhang G. Analysis of antigenicity and pathogenicity reveals major differences among QX-like infectious bronchitis viruses and other serotypes. Vet Microbiol. 2017;203:167-73.

63. Khanh NP, Tan SW, Yeap SK, Lee HJ, Choi KS, Hair-Bejo M, Bich TN, Omar AR. Comparative pathogenicity of Malaysian QX-like and variant infectious bronchitis virus strains in chickens at different age of exposure to the viruses. J Comp Pathol. 2018;161:43-54.

64. Fulton RM, Reed WM, Thacker $\mathrm{HL}$. Cellular response of the respiratory tract of chickens to infection with Massachusetts 41 and Australian T infectious bronchitis viruses. Avian Dis. 1993;37(4):951-60.

65. Amarasinghe A, Abdul-Cader MS, Nazir S, De Silva Senapathi U, van der Meer F, Cork SC, Gomis S, Abdul-Careem MF. Infectious bronchitis corona virus establishes productive infection in avian macrophages interfering with selected antimicrobial functions. PLoS One. 2017;12(8):e0181801.

66. Amarasinghe A, Abdul-Cader MS, Almatrouk Z, van der Meer F, Cork SC, Gomis S, Abdul-Careem MF. Induction of innate host responses characterized by production of interleukin (IL)-1 beta and recruitment of macrophages to the respiratory tract of chickens following infection with infectious bronchitis virus (IBV). Vet Microbiol. 2018;215:1-10.

67. da Silva SEL, Ferreira HL, Garcia AF, Silva FES, Gameiro R, Fabri CUF, Vieira DS, Cardoso TC. Mitochondrial bioenergy alterations in avian HD11 macrophages infected with infectious bronchitis virus. Arch Virol. 2018;163(4):1043-9.

68. Han X, Tian Y, Guan R, Gao W, Yang X, Zhou L, Wang H. Infectious bronchitis virus infection induces apoptosis during replication in chicken macrophage HD11 cells. Viruses. 2017;9(8):198.

69. Kameka AM, Haddadi S, Kim DS, Cork SC, Abdul-Careem MF. Induction of innate immune response following infectious bronchitis corona virus infection in the respiratory tract of chickens. Virology. 2014;450-451:114-21.

70. Meir R, Maharat O, Farnushi Y, Simanov L. Development of a real-time TaqMan ${ }^{\circledR}$ RT-PCR assay for the detection of infectious bronchitis virus in chickens, and comparison of RT-PCR and virus isolation. J Virol Methods. 2010;163(2):190-4.

71. Breslin JJ, Smith LG, Fuller FJ, Guy JS. Sequence analysis of the Turkey coronavirus nucleocapsid protein gene and 3' untranslated region identifies the virus as a close relative of infectious bronchitis virus. Virus Res. 1999; 65(2):187-93.

72. Klein D. Quantification using real-time PCR technology: applications and limitations. Trends Mol Med. 2002:8(6):257-60.

73. Reed $\amalg$, Muench $H$. A simple method of estimating fifty per cent endpoint. Am J Epidemiol. 1938;27(3):493-7. 